\title{
The Influence of Corpus Luteum Size on the Conception in Embryo Transfer Recipient Cows
}

\author{
Erkan Say ${ }^{1, *(D)}$, Mehmet Ferit Ozmen² ${ }^{(D}$, Hakan Sagırkaya ${ }^{3}$ \\ ${ }^{1}$ Eastern Mediterranean Agricultural Research Institute, Adana, Turkey \\ ${ }^{2}$ Department of Reproduction and Artificial Insemination, Faculty of Veterinary Medicine, Dicle University, Diyarbakır, Turkey \\ ${ }^{3}$ Department of Reproduction and Artificial Insemination, Faculty of Veterinary Medicine, Uludag University, Bursa, Turkey
}

\section{Article History}

Received: 5 May 2021

Accepted: 12 Nov 2021

First Online: 7 Dec 2021

\section{Corresponding Author*}

Tel.: +905342248004

E-mail: erkan_say99@hotmail.com

\section{Keywords}

Corpus luteum

Embryo transfer

Recipient cow

\begin{abstract}
The aim of study was to investigate the effect of corpus luteums (CL) size that detected before embryo transfer on conception in recipient Holstein cows. The recipient cows utilized had at least one birth and aged 3-8 years old. PGF2 $\alpha$ was injected 2 times space 14 days apart to cows and 87 cows which show estrous symptoms were determined as recipient. Fresh embryos were transferred after estrous in $6^{\text {th }} 8^{\text {th }}$ days. Ovaries were examined by ultrasound before transfer and $\mathrm{CL}$ sizes were measured. A scale of ' ++++ ' were set as a result of measurements. Recipient cows were into 3 groups. The first group was named as $\mathrm{CL} 2+(n=25)$ and consisted of cows with ' ++ ' $(\geq 15-20<\mathrm{mm})$ size CL. The second group was named as $\mathrm{CL} 3+(n=52)$ and consisted of cows with ' +++ ' $(\geq 20-25<\mathrm{mm})$ size CL. The third group was named as CL4+ $(n=10)$ and consisted of cows with ' ++++ ' $(\geq 25 \mathrm{~mm}$ ) size $\mathrm{CL}$. The embryos were transferred to the uterine horn on the side of the CL (ipsilateral). Pregnancy rate was respectively $36 \%, 46.2 \%$ and $40 \%$ for groups. No statistically significant difference was found between groups in terms of the effect of $\mathrm{CL}$ on conception $(P>0.05)$. As a result, it was concluded that the size of the corpus luteum has no effect on the conception of cows utilized as recipients in embryo transfer.
\end{abstract}

\section{Introduction}

Bovine embryo transfers attempt to produce a number of high-quality calves by first selecting a cow (donor) with good genetic creation, a sturdy body conformation and outstanding strength, then artificially inducing the production of a number of fertilized eggs (superovulation) and finally transferring them into the uteri of other cows or heifers (recipients). This helps to quickly improve the breed as well as increase profits (Kanagawa et al., 1995). One of the most important ways providing genetic progress rapidly in dairy cattle and increasing number of selected male and female in the herd is embryo transfer applications (Akyol, 2001; Pabuçcuoğlu, 2013; Seidel and Seidel, 1991; Tekeli, 2010). Furthermore, embryo transfer is the most important modern technique used to increase the success of animal breeding in the most effective way (Bülbül and Dursun 2005). The most important goal of bovine embryo transfer is to obtain oocytes and embryos of high quality from superior dams that will result in the birth of healthy calves (Santos et al., 2008). Normally, while a cow can breed one calf in a year, at least 5 times the number of offspring that can be obtained throughout life can be obtained by embryo transfer (Seidel and Seidel 1991; Tekeli, 2010). The successful transfer of embryos into lactating dairy cattle has shown beneficial effects in improving fertility in dairy cattle, especially during summer heat stress. The transfer of an embryo could bypass certain causes of infertility (i.e., fertilization failure and early embryonic loss) (Bilby, 2010).

After ovulation, the corpus luteum $(\mathrm{CL})$ is formed under the influence of $\mathrm{LH}$ from follicle residues. The follicle cavity is filled with blood vessels and the size of the granulosa cells increases. Progesterone is indispensable for normal cycle in cow, and it is primarily responsible hormone for maintaining pregnancy after conception. Around 16 days following ovulation, PGF $2 \alpha$ secreted from the non-pregnant uterine endometrium 
initiates regression of the corpus luteum and this event is called luteolysis (Ptaszynaska, 2009).

The ovarian follicle wall, consisting of granulosa cells and theca cells, vascularizes and luteinizes after ovulation to form a corpus luteum. This temporary steroid-producing gland undergoes marked structural and functional changes in a short time-span during its development, functional life and regression (O'Shea et al., 1987). There is a high correlation between plasma progesterone concentration and corpus luteum mass, volume and histomorphology (Singh et al., 1997). For pregnancy to be established in cattle, the embryo has to be inhibited the development of the luteolytic mechanism and maintain the secretion of progesterone by the corpus luteum (Silva et al., 2002).

A successful pregnancy depends on complicated interactions between the mother and the conceptus in the genital tract in ruminants. During maternal pregnancy recognition, the viable embryo must be able to interrupt the luteolysis with the production of bovine trophoblastic interferon and promoting the action of a functional $\mathrm{CL}$ that synthesizes adequate levels of progesterone (P4), a hormone that plays a vital role in early gestation, since it stimulates and maintains the functions necessary for the growth of the conceptus, implantation and placentation. An ovulatory follicle with appropriate size can become, after ovulation, a functional $C L$ that will secrete $\mathrm{P} 4$ with a positive effect on the establishment of pregnancy (Monroy et al., 2018).

The uterine microenvironment provides suitable medium for embryos developing only during the luteal stage of the estrus cycle. Therefore, the harmonization of the physiological state of the donor and the recipient in the embryo transfer operations, that is, synchronization, is the basic principle in the success of the method (McGeady et al., 2011).

Accordingly, our hypothesis is that different corpus luteum sizes will affect the conception rate. Therefore, the aim of the study was to evaluate the CL size affect or not the conception rate on recipient cows.

\section{Materials and Methods}

\section{Materials}

In this study, embryos obtained from lactating cows as selected donors in Eastern Mediterranean Agricultural Research Institute-Adana, Turkey were transferred freshly to cows in this institute. The cows were Holstein cows, and the age of the recipient cows used in the study ranged from 3 to 8 years. 87 cows selected from the farm were utilized in the study. While selecting the animals to be used in the study, the genital examinations were performed by transrectal ultrasonography using a portable ultrasound with a 5 $\mathrm{MHz}$ linear probe (Ultrasonic scanner, HS-101V, Honda, JAPAN) to determine if there is a pathological condition.

In the farm, cows are housed in open barns and fans are used with water spraying as cooling systems to minimize the heat stress, which is an important effect of the Mediterranean climate. Wheat straw, alfalfa, corn silage and vetch as roughage and concentrated feed (it contains barley, whaet, corn, sunflower meal, soybean meal and mineral-vitemans) with $18 \%$ protein produced in the enterprise was used in ration. Water was provided with automatic waterers as ad libitum.

\section{Methods}

The ovarian examinations of the recipient cows in the study were performed with ultrasound. CLs were evaluated on the scale of '++++' in terms of quality and were calculated by size in millimeter. The corpus luteum size was determined firstly by measuring 2 furthest point from right to left and 2 furthest point from top to bottom. Then the average of these two measures was taken. The cows to be utilized as recipients in the study were divided into 3 groups. The first group was named as $\mathrm{CL} 2+(n=25)$ and was consisted of cows with $\mathrm{CL}$ of ' ++ ' $(\geq 15-20<\mathrm{mm})$ size. The second group was named as $\mathrm{CL3}+(\mathrm{n}=52)$ and cows with $\mathrm{CL}$ of ' +++ ' $^{\prime}(\geq 20-25<\mathrm{mm})$ size were used as recipients. Finally, the group consisting of group 3 carriers was named as $\mathrm{CL} 4+(n=10)$ and was selected of cows with a size of ' ++++ ' $(\geq 25 \mathrm{~mm})$.

The cows that could be included in the study were injected PGF2 $\alpha$ twice with an interval of 14 days. These cows were followed and those who showed estrus symptoms were determined and recorded. The presence of quality $\mathrm{CL}$ in these cows detected was determined by ultrasound examination on the day of transfer. The transfers were applied to the recipients with high quality and suitable CL. In ovarian examinations, CLs were evaluated in terms of diameter, quality, presence of antrum and on which side it was located (Figure 1). The fresh embryos were transferred to the horn on the side where $\mathrm{CL}$ was detected (ipsilaterally).

\section{Statistical Analysis}

SPSS package program version 25 (SPSS Inc., Chicago, USA) was used for statistical analysis of the study. Pregnancy status of the groups was statistically compared by Chi-square test.

\section{Results and Discussion}

Twenty-eight days after embryos were transferred to recipient cows (35 days after estrus), pregnancy examinations were performed using the recto-vaginal method using ultrasound. 37 of 87 (42.5\%) recipient cows that were embryo transferred were diagnosed to be pregnant. The relationships between the groups' corpus luteum sizes and conception are shown in Table 1. When the pregnancies were evaluated as a group, 9 pregnancies were obtained from 25 transfers in the CL2 + group and a $36 \%$ pregnancy rate was obtained. 24 pregnancies were diagnosed from 52 transfers in CL3 + 
Table 1. Pregnancy rates in groups according to different corpus luteum diameters $(P>0.05)$.

\begin{tabular}{ccccc}
\hline Groups & $\mathbf{n}$ & Pregnant & Non-Pregnant & Pregnancy Rate \\
\hline CL2+ (Group I) & 25 & 9 & 16 & $36.00 \%$ \\
CL3+ (Group II) & 52 & 24 & 28 & $46.20 \%$ \\
CL4+ (Group III) & 10 & 4 & 6 & $40.00 \%$ \\
\hline Total & $\mathbf{8 7}$ & $\mathbf{3 7}$ & $\mathbf{5 0}$ & $\mathbf{4 2 . 5 0 \%}$ \\
\hline
\end{tabular}

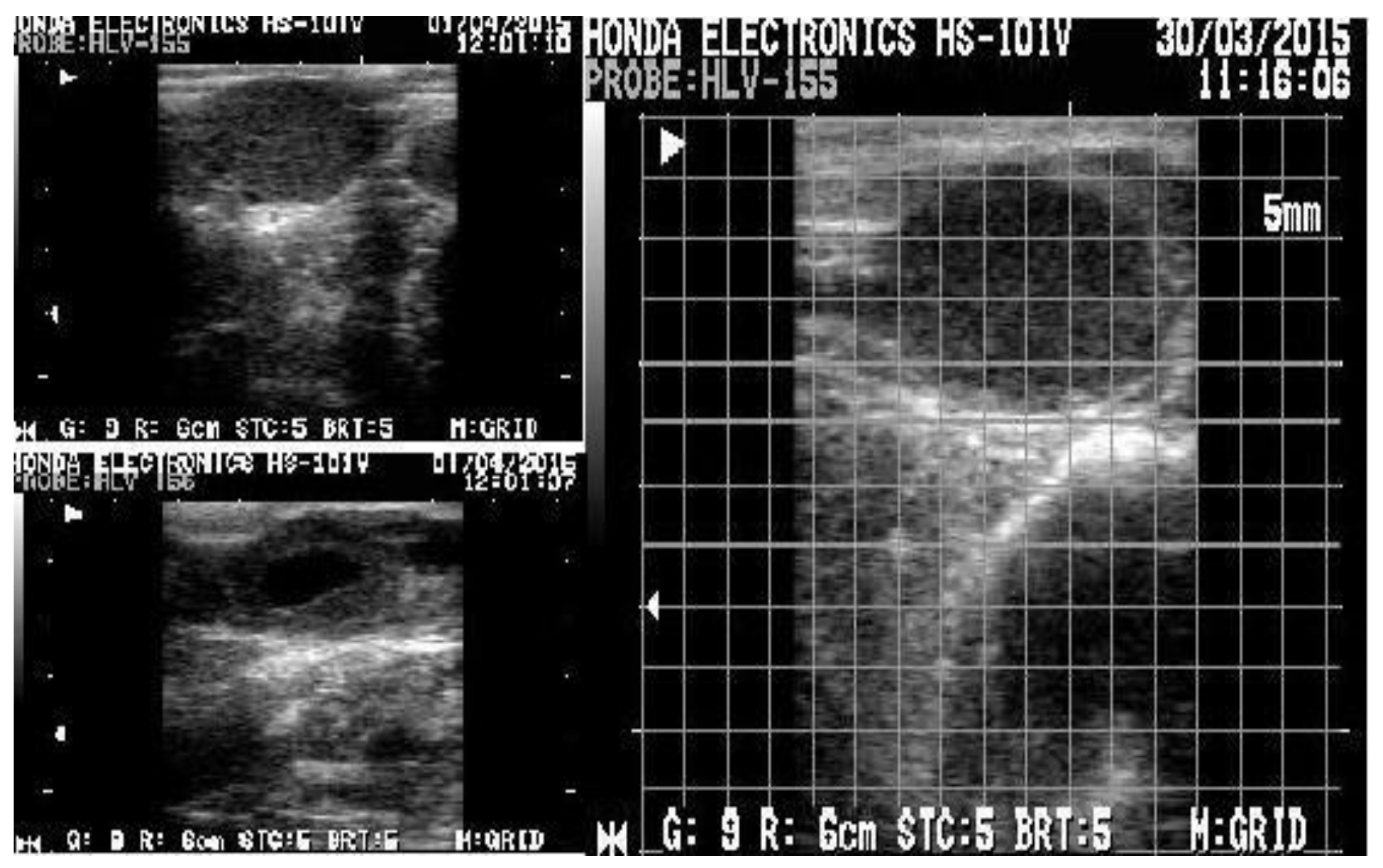

Figure 1. Ultrasound image of the corpus luteums.

group and the pregnancy rate was determined as $46.2 \%$. Finally, in the CL4+ group, 4 pregnancies in 10 cows were determined and the pregnancy rate was found to be $40 \%$. When the pregnancy rates were compared, there was no statistically difference between the groups $(P>0.05)$. However, even an extra pregnancy is important in high-cost applications such as ET.

This study was carried out to search whether corpus luteum size of recipient Holstein cows which were transferred fresh embryo has an effect on conception rate. In our study, corpus luteum size did not affect the conception rate in recipient cows. The relationship between corpus luteum size, progesterone concentrations, and pregnancy rates in recipients is still uncertain, and a lot of research has been made on this subject (Hasler et al., 1980; Ramsen and Roussel, 1982). There are different ideas regarding whether high (>6.0 $\mathrm{ng} / \mathrm{mL}$ ) or low $(<2.0 \mathrm{ng} / \mathrm{mL}$ ) blood progesterone concentrations affect pregnancy rates (Siqueira et al., 2009).
Good, bad and cystic corpus luteum quality (good is big size, bad is small size) in cows had no effect on pregnancy rate in embryo transfer (Ramsen and Roussel, 1982). In our study, the corpus luteum size had no effect on pregnancy rate similarly Ramsen and Roussel (1982) study. They also transferred embryos to recipients that have cystic corpus luteum and found no different.

In a study investigating the effects of estrus detection and development of corpus luteum on conception for embryo transfer in recipient cows, it is evaluated the rates of conception by transferring the embryos at the age of 6.5-9 days between November 1983 and May 1984 by non-surgical method. Embryos were transferred to 19 herds in 10 states of the USA. The estrus of recipients was synchronized using PGF2 $\alpha$. The estrus determinations of the recipients were recorded within \pm 60 hours (before and after the donors showed estrus) simultaneously with the donor estrus. 
The corpus luteum was rated as 1 ) normal, 2) suspect or 3 ) non-palpable during transfer. When the pregnancy rates of the groups were compared, it was observed that the size of the corpus luteum had no effect on conception as in the current study (Nelson and Nelson, 1985).

There are studies evaluating corpus luteum number, size, and serum progesterone concentration. There are different situations regarding blood progesterone levels. It has been determined that high P4 concentration does not increase conception rate in recipients with embryo transfer, on the contrary, a decrease in pregnancy rates in animals with the highest P4 levels (Siqueira et al., 2009; Nogueira et al., 2004).

\section{Conclusion}

In this study, it was determined that the quality (size) assessment of corpus luteum did not differ in terms of the rate of pregnant and non-pregnant cows in accordance with the literature, in recipient cows which have different sizes corpus luteum for embryo transfer. But a recipient with a CL size of $20-25 \mathrm{~mm}$ with a numerically higher pregnancy should be preferred.

\section{Acknowledgement}

Ethic Committee Report was given by Cukurova University Local Ethic Committee of Experimental Animals for this study. The committee met on 25.08.2015. This study is a part of doctoral project named 'Searching of Pregnancy Rate in Repeat Breeder Cows by Embryo Transfer Practices'. And this study is a part of the mentioned work. So, we utilized the same committee report for this study too.

\section{References}

Akyol, N. (2001). Using hormon in cattle embryo transfer (Article in Turkish). Lalahan Hayvancılık Araştırma Enstitüsü Dergisi 44(1): 95-104.

Bülbül, B., Dursun, Ş. (2005). Factors affecting superovulation response in cows (Article in Turkish). Hayvancılık Araştırma Dergisi 15 (1): 16-25.

Bilby, T.R. Improving fertility in the repeat breeder. http://articles.extension.org/pages /28606/improving-fertility-in-the repeatbreeder\#Embryo_Transfer. Erişim Tarihi: 05.05.2017.

Hasler, J.F., Browen, R.A., Nelson, L.D., Seidel, G.E. (1980). Serum progesterone concentrations in cows receiving embryo transfers. Journal of Reproduction and Fertility 58: 71-77. https://doi.org/10.1530/jrf.0.0580071

Kanagawa, H., Shimohira, I., Saitoh, N. (1995). Manual of bovine embryo transfer. National Livestock Breeding Center MAFF, JICA-Japan, pp: 1-34.

McGeady, T.A., Quinn, P.J., Fitz Patrick, E.S., Ryan, M.T.
(2011). Veterinary embryology. Translate: Çelik i. 1. Baskı. Malatya Medipres Matbaacılık Ltd. Şti. s:96

Monroy, M.G., Jimenez, C.E., Hernandez, A.V. (2018). Follicular and luteal morphometry, progesterone concentration and early gestation in Holstein cows (Bos Taurus) at high altitude in the tropics (Colombia). Revista Mvz Cordoba; 23(2).

Nelson, L.D., Nelson, C.F. (1985). Effect of estrus detection and corpus luteum development on pregnancy rates in bovine embryo recipients. Theriogenology; 23(1):212 (Abstract). https:// doi.org/10.1016/ 0093691x (85)90118-9.

Nogueira, M.F.G., Melo, D.S., Carvalho, L.M., Fuck, E.J., Trinco, L.A., Barros, C.M. (2004). Do high progesterone concentrations decrease pregnancy rates in embryo recipients synchronized with PGF2a and eCG? Theriogenology; 61: 1283-1290. https://doi.org /10.1016/j.theriogenology.2003.07.012.

O'Shea, J.D., 1987. Heterogeneous cell types in the corpus luteum of sheep, goats and cattle. J Reprod Fertil Suppl, 34: 71-85.

Pabuçcuoğlu, S. Reproduction control and embryo transfer in cows, aves.istanbul.edu.tr/ImageOfByte.aspx?R esim $=8 \& S S N O=7 \&$ USER=1653. Erişim Tarihi: 04.05.2017. (Article in Turkish).

Ptaszynska, M. (2009). Reproduction in Ruminants. Translate: Fındık M, Gültiken N, Ay SS et al, 10. Baskı, İstanbul.; s: 25-26.

Ramsen, L.G., Roussel, J.D. (1982). Pregnancy pates relating to plasma progesterone levels in recipient heifers at day of transfer. Theriogenoeogy; 18 (3): 365-372. https://doi.org/10.1016/0093-691x(82) 90149-2.

Santos, J.E.P., Cerri, R.L.A., Sartori, R. (2008). Nutritional management of the donor cow. Theriogenology; 69: 88-97. https://doi.org/ 10.1016/j.theriogenology. 2007.09.010.

Seidel, G.E., Seidel, S.M. Training Manual for embryo transfer in Ccttle, http://www.fao.org/DOCREP/004/ T0117E/T0117E00.htm. Erişim Tarihi: 26.05.2017.

Silva, J.C., Costa, L.L., Silva, J.R. (2002). Plasma progesterone profiles and factors affecting embryo-fetal mortality following embryo transfer in dairy cattle. Theriogenology; 58: 51-59. https://doi.org/10.1016/s0093691x (02)00906-8.

Singh, J., Pierson, R.A., Adams, G.P. (1997). Ultrasound image attributes of the bovine 
corpus luteum: structural and functional correlates. Journal of Reproduction and Fertility; 109: 35-44. https://doi.org/10.1530/jrf. 0.1090035.

Siqueira, L.G.B., Torres, C.A.A., Souza, E.D., Monteiro, P.L.J., Arashiro, E.K.N, Camargo, L.S.A, Fernandes, C.A..C, Viano, J.H.M. (2009). Pregnancy rates and corpus luteum-related factors affecting pregnancy establishment in bovine recipients synchronized for fixedtime embryo transfer. Theriogenology; 72:949958. https://doi.org/10.1016/j. theriogenology.2009.06.013.

Tekeli, T. (2010). Embryo transfer. Editör: Alaçam E, Obstetric and Infertility in Pets.7. Baskı, Ankara Medisan Yayınları, pp. 81-97. (Book in Turkish). 